Article

\title{
Investigation of Flame Retardant Flexible Polyurethane Foams Containing DOPO Immobilized Titanium Dioxide Nanoparticles
}

\author{
Quanxiao Dong ${ }^{1,2}$, Keyu Chen ${ }^{1}$, Xiaodong Jin ${ }^{1}$, Shibing Sun ${ }^{1, *}$, Yingliang Tian ${ }^{1}$, \\ Feng Wang ${ }^{3, *}$, Peng Liu ${ }^{3}$ and Mingshu Yang ${ }^{3}$ \\ 1 College of Materials Science and Engineering, Beijing University of Technology, Beijing 100024, China; \\ quanxiao185@iccas.ac.cn (Q.D.); summercky@126.com (K.C.); jinxiaodong@bjut.edu.cn (X.J.); \\ tianyl@bjut.edu.cn (Y.T.) \\ 2 Railway Engineering Research Institute, China Academy of Railway Sciences, Beijing 100081, China \\ 3 National Laboratory for Molecular Science, CAS Key Laboratory of Engineering Plastics, Institute of \\ Chemistry, Chinese Academy of Sciences, Beijing 100190, China; liupeng@iccas.ac.cn (P.L.); \\ yms@iccas.ac.cn (M.Y.) \\ * Correspondence: sunshibing@bjut.edu.cn (S.S.); wangfeng0822@iccas.ac.cn (F.W.); \\ Tel.: +86-10-5184-9505 (S.S.); +86-10-8261-2927 (F.W.)
}

Received: 29 November 2018; Accepted: 28 December 2018; Published: 5 January 2019 updates

\begin{abstract}
In this work, a multi-functional nanoparticle ( $\left.\mathrm{TiO}_{2}-\mathrm{KH} 570-\mathrm{DOPO}\right)$ has been successfully synthesized through the attachment of 9,10-dihydro-9-oxa-10-phosphaphenanthrene-10-oxide (DOPO)-methacryloxy propyl trimethoxyl silane on the surface of titanium dioxide $\left(\mathrm{TiO}_{2}\right)$. Supercritical carbon dioxide was used as the solvent in order to increase the grafting level. The chemical structure of $\mathrm{TiO}_{2}-\mathrm{KH} 570-\mathrm{DOPO}$ was fully characterized using Fourier transform infrared spectra, thermogravimetric analysis and transmission electron microscopy. The modified $\mathrm{TiO}_{2}$ was incorporated into flexible polyurethane foam (FPUF). The fire performance of FPUF blends was evaluated using microscale combustion calorimetry. Peak heat release rate and total heat release values were reduced from $657.0 \mathrm{~W} / \mathrm{g}$ and $28.9 \mathrm{~kJ} / \mathrm{g}$ for neat FPUF sample to $519.2 \mathrm{~W} / \mathrm{g}$ and $26.8 \mathrm{~kJ} / \mathrm{g}$ of FPUF specimen containing $10 \mathrm{wt} \%$ of $\mathrm{TiO}_{2}-\mathrm{KH} 570-\mathrm{DOPO}$. Analysis of thermal stability and the observation of char formation suggests that $\mathrm{TiO}_{2}-\mathrm{KH} 570-\mathrm{DOPO}$ is active in the condensed phase.
\end{abstract}

Keywords: titanium dioxide; polyurethane; surface modification; supercritical carbon dioxide; flame retardant

\section{Introduction}

Due to high resilience and low density, flexible polyurethane foams (FPUFs) are widely used in everyday items, such as vehicles and furniture [1-6]. However, the inherent structure of FPUF (large surface area and good air permeability) makes it highly flammable [5], which presents a threat to both the performance and durability of products containing this material. Therefore, developing effective flame retardant FPUPs is urgently needed.

The incorporation of flame retardants has been widely applied to enhance the fire resistance of FPUFs. Halogen-containing, phosphorus-based, intumescent flame retardants (IFR), metal hydroxides and nanoparticles [7-9] have all been used to improve the fire safety of polyurethane materials. Halogen-containing flame retardants have gradually been replaced by halogen-free flame retardants due to increased environmental concerns and potential negative health effects of these materials. However, high loading of inorganic halogen-free flame retardants (such as metal hydroxides) obviously often degrades the mechanical performance of the polymer matrix. Recently, the surface treatments 
of FPUF through layer-by-layer, plasma and sol-gel techniques have received increasing attention due to high efficiency and rapid preparation [10]. Branched polyethylenimine (BPEI), chitosan and poly(acrylic acid) (PAA) have all been used to improve the flame retardant performance of PU foams [11]. However, the durability of surface coatings remains a huge challenge. Washing, chemical etching and physical abrasion all degrade the surface coating [12].

Incorporation of titanium dioxide $\left(\mathrm{TiO}_{2}\right)$ exerts positive effects on the charring process for polymer matrices undergoing combustion [13-15]. A problem is that $\mathrm{TiO}_{2}$ particles do not disperse well within most polymer matrices because of the polarity differences. As a result, surface modification with silicanes, such as $\gamma$-aminopropyl triethoxysilane (KH550) and methacryloxy propyl trimethoxyl silane (KH570), is needed for incorporation of $\mathrm{TiO}_{2}$. 9,10-dihydro-9-oxa-10-phosphaphenanthrene-10-oxide (DOPO) has been proven to be an effective flame retardant in both the gas and condensed phase [16-18]. The presence of KH570 facilitates the dispersion of the flame retardant in the polymer matrix $[19,20]$. In previous work, KH570-DOPO was successfully prepared and applied to increase the fire resistance of polypropylene [21,22]. However, the grafting level was not satisfactory, which might be the reason for the low efficiency of KH570-DOPO in this system. In order to overcome this drawback, the use of supercritical carbon dioxide $\left(\mathrm{SCCO}_{2}\right)$ as a solvent has been envisaged [23-25]. $\mathrm{SCCO}_{2}$ is a commonly used supercritical fluid with moderate critical pressure and temperature $(\mathrm{P}=7.4 \mathrm{MPa}, \mathrm{Tc}=304.2 \mathrm{~K}$, respectively), that is an excellent solvent for most alkoxysilanes [26]. Moreover, the $\mathrm{SCCO}_{2}$ properties of gas-like diffusivity and viscosity, and zero surface tension, facilitate the complete wetting of the internal surface of the mesoporous aggregates formed by nanoparticles.

In this work, $\mathrm{KH} 570-\mathrm{DOPO}$ was selected as a surface modifier for $\mathrm{TiO}_{2}$ in order to improve its compatibility with the matrix. Moreover, $\mathrm{SCCO}_{2}$ was used as the solvent for the effective production of $\mathrm{TiO}_{2}-\mathrm{KH} 570-\mathrm{DOPO}$. The obtained nanoparticles were then incorporated into FPUF. The flame retardant performances and thermal stability of FPUF blends were characterized. The morphologies of the residual char were observed and a mode of action for the flame retardant was also proposed.

\section{Experimental}

\subsection{Materials}

$\mathrm{TiO}_{2}$ nanometric particles $(21 \mathrm{~nm})$ were supplied by Degussa (Commercial grade P25). 3-methacryloxypropyltrimethoxysilane (KH570) was obtained from Energy Chemical Co. Ltd., Shanghai, China. DOPO was supplied by H\&G Chemical Co. Ltd., Jiangsu, China. Polybasic alcohol compositions (PO 715) were obtained from Shandong Ogasen New Material Co. Ltd., Shandong, China. Isocyanate (8725) was supplied by Wanhua Chemical Group Co. Ltd., Shandong, China.

\subsection{Measurements}

Fourier transform infrared (FTIR) spectra were recorded using a Bruker Tensor 27 FTIR spectrometer with $1 \mathrm{~cm}^{-1}$ resolution over 128 scans for $\mathrm{KBr}$ disk samples in the range of 4000 to $500 \mathrm{~cm}^{-1}$.

Thermogravimetric analysis (TGA) was carried out using a Q50 apparatus from TA Instruments at a heating rate of $10^{\circ} \mathrm{C} / \mathrm{min}$ under an air atmosphere with the temperature range from ambient temperature over $750^{\circ} \mathrm{C}$.

Transmission electron microscopy (TEM) observation was carried out with a Hitachi H-800 electron microscope. The analysis was performed at $200 \mathrm{kV}$ acceleration voltage and bright field illumination under ambient temperature, and the samples were prepared by dispersing the particles into alcoholic solution with ultrasonic treatment.

Microscale combustion calorimetry (MCC) was carried out using an FAA Micro calorimeter (FAA Fire testing technology, East Grinstead, UK) operated at $1{ }^{\circ} \mathrm{C} / \mathrm{s}$ to $750{ }^{\circ} \mathrm{C}$ in the pyrolysis zone according to ASTM D7309 method A. The combustion zone was set at $900{ }^{\circ} \mathrm{C}$. Oxygen and nitrogen flow rates were set at 20 and $80 \mathrm{~mL} / \mathrm{min}$, respectively. 
The digital photographs of calcined FPUF residues recorded using a TF-1450 thermal camera (Xiangyi instrument company, Xiangtan, China). The sample was heated to a certain temperature at the rate of $10{ }^{\circ} \mathrm{C} / \mathrm{min}$. Once the temperature had equilibrated at the desired point, a picture of this residue was recorded.

\subsection{Preparation of KH570-DOPO}

KH570-DOPO was prepared as previously reported [21]. Briefly, DOPO, KH570 (molar ration 1.1:1) and triethylamine were placed in a culture dish before putting them into a sealed supercritical carbon dioxide $\left(\mathrm{SCCO}_{2}\right)$ reaction kettle. The reaction temperature was $60^{\circ} \mathrm{C}$, the pressure was 12 $\mathrm{MPa}$ and the reaction time was controlled for $2 \mathrm{~h}$. After filtering, washing and drying, the products of KH570-DOPO were obtained.

\subsection{Preparation of $\mathrm{TiO}_{2}-\mathrm{KH} 570-\mathrm{DOPO}$}

$\mathrm{TiO}_{2}(2.5 \mathrm{~g})$ and $\mathrm{KH} 570-\mathrm{DOPO}$ (2.5 g) were dispersed into a culture dish. The same condition was used to synthesize the $\mathrm{TiO}_{2}-\mathrm{KH} 570-\mathrm{DOPO}$ nanoparticles. The reaction temperature, pressure and time were settled to $60{ }^{\circ} \mathrm{C}, 12 \mathrm{MPa}$ and $2 \mathrm{~h}$, respectively. The precipitates were then filtered and washed several times with toluene ( $200 \mathrm{~mL}$, six times) for ensuring that any absorbed KH570-DOPO was completely removed. The products were dried at $80^{\circ} \mathrm{C}$ for $24 \mathrm{~h}$, obtaining $\mathrm{TiO}_{2}-\mathrm{KH} 570-\mathrm{DOPO}$. The preparation process was shown in Figure 1.

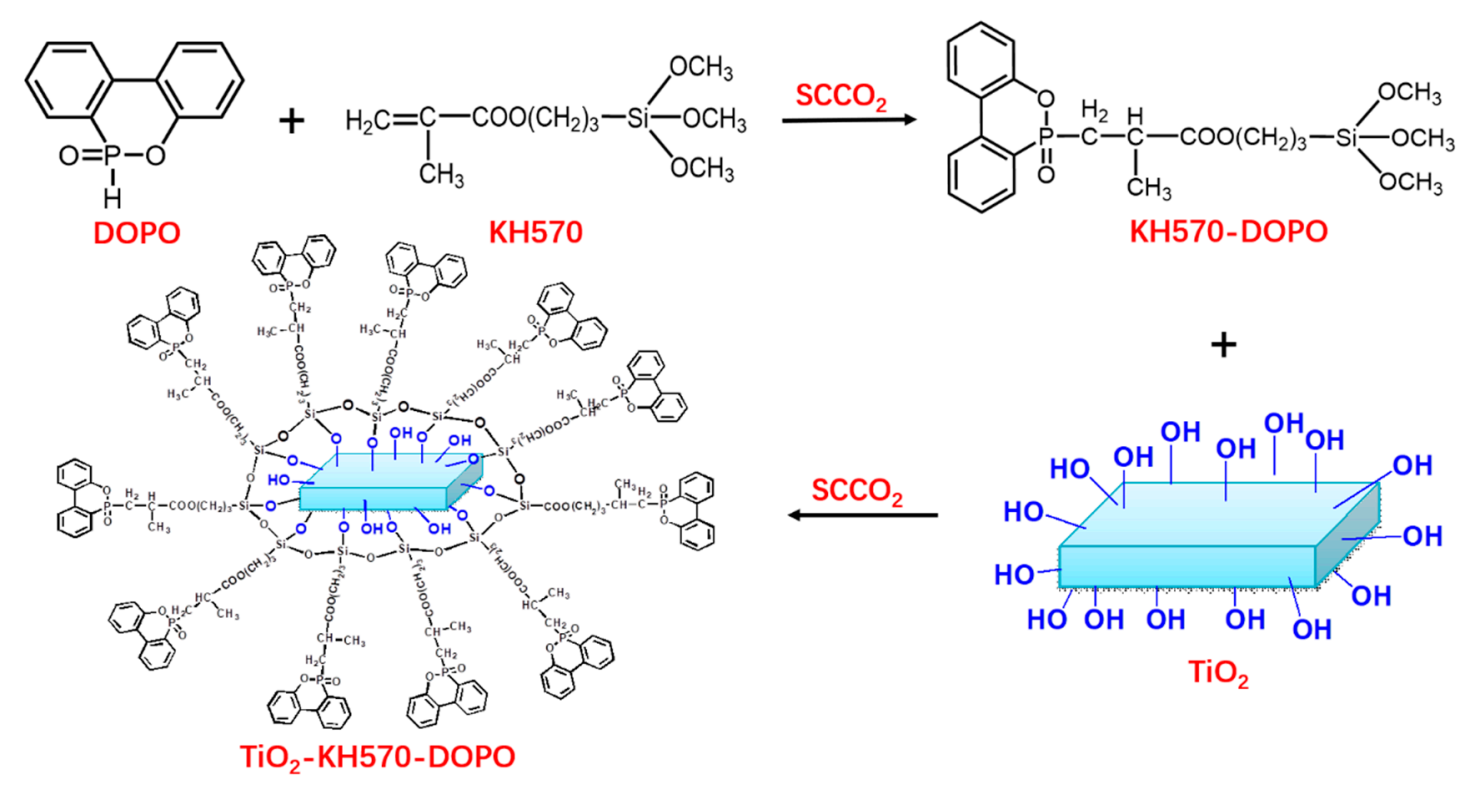

Figure 1. Process of $\mathrm{TiO}_{2}-\mathrm{KH} 570-\mathrm{DOPO}$.

\subsection{Preparation of FPUF/TiO ${ }_{2}$ Blends}

Neat FPUF and the flame retardant FPUF blends were prepared by a conventional one-pot and free-rise method. Polybasic alcohol compositions and isocyanate were mixed and stirred using an electric stirrer at room temperature. Then the mixtures were poured into an aluminum cube with a dimension of $100 \mathrm{~mm}^{*} 100 \mathrm{~mm}^{*} 100 \mathrm{~mm}$. After that, the FPUF blends were placed in an oven at $70{ }^{\circ} \mathrm{C}$ for $24 \mathrm{~h}$ in order to complete the polymerization reaction. As for the FPUF/ $\mathrm{TiO}_{2}-\mathrm{KH} 570-\mathrm{DOPO}$ blends, a similar procedure was used and the loading of nanoparticles was settled at 1,5 and $10 \mathrm{wt} \%$ respectively. These samples were noted as S0, S1, S5 and S10, correspondingly. The foam density was normalized to about $0.20 \mathrm{~g} / \mathrm{cm}^{3}$ by varying the dosage of foam agent. The composites were prepared with a constant $\mathrm{NCO}$ index (110). 


\section{Results and Discussions}

\subsection{Characterization of $\mathrm{TiO}_{2}-\mathrm{KH} 570-\mathrm{DOPO}$}

\subsubsection{FTIR Analysis}

The FTIR spectra of $\mathrm{KH} 570-\mathrm{DOPO}, \mathrm{TiO}_{2}$ and $\mathrm{TiO}_{2}-\mathrm{KH} 570-\mathrm{DOPO}$ are shown in Figure 2. As reported, the appearance of $\mathrm{C}=\mathrm{O}\left(1708 \mathrm{~cm}^{-1}\right)$ from $\mathrm{KH} 570$ and the disappearance of $\mathrm{P}-\mathrm{H}\left(2427 \mathrm{~cm}^{-1}\right)$ indicate the reaction between DOPO and $\mathrm{KH} 570[27,28] . \mathrm{TiO}_{2}$ exhibits a Ti-O peak at $405 \mathrm{~cm}^{-1}$. However, this peak shows a lower intensity in the spectrum of $\mathrm{TiO}_{2}-\mathrm{KH} 570-\mathrm{DOPO}$. Moreover, the peaks from $\mathrm{KH} 570-\mathrm{DOPO}$ can also be found in $\mathrm{TiO}_{2}-\mathrm{KH} 570-\mathrm{DOPO}$ (such as $\mathrm{C}=\mathrm{O}$ and $\mathrm{C}-\mathrm{H}$ ). It was indicated that KH570-DOPO was immobilized onto the surface of $\mathrm{TiO}_{2}$.

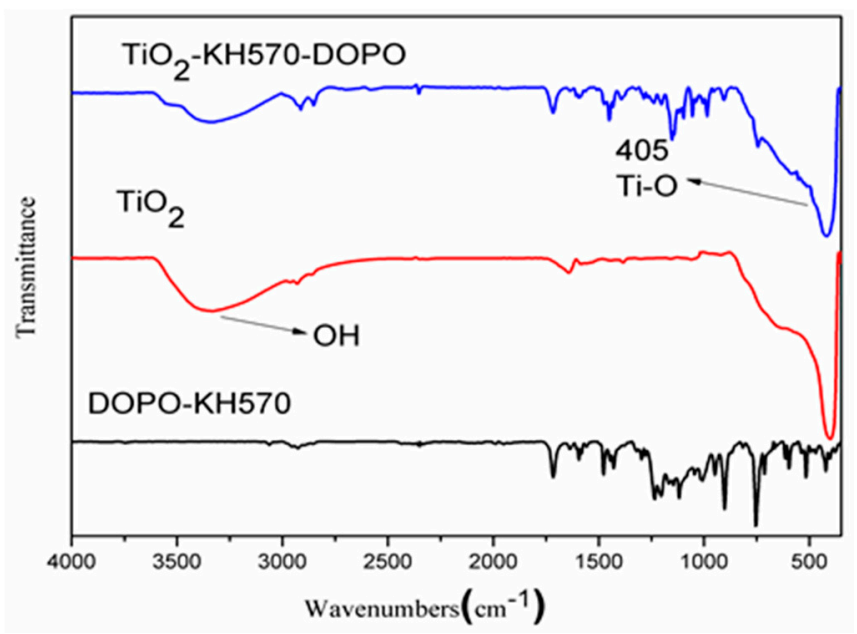

Figure 2. Fourier transform infrared (FTIR) spectra of $\mathrm{TiO}_{2}, \mathrm{KH} 570-\mathrm{DOPO}$ and $\mathrm{TiO}_{2}-\mathrm{KH} 570-\mathrm{DOPO}$.

\subsubsection{TGA Analysis}

The TGA curves of $\mathrm{TiO}_{2}$ and $\mathrm{TiO}_{2}-\mathrm{KH} 570-\mathrm{DOPO}$ under an air atmosphere are shown in Figure 3. For neat $\mathrm{TiO}_{2}$, rare weight loss can be observed. However, the thermal stability of $\mathrm{TiO}_{2}-\mathrm{KH} 570-\mathrm{DOPO}$ is significantly reduced. It shows a $53.0 \%$ residue at $750{ }^{\circ} \mathrm{C}$ because of the introduction of $\mathrm{KH} 570-\mathrm{DOPO}$. Moreover, the grafting rate of $\mathrm{KH} 570-\mathrm{DOPO}$ on the surface of $\mathrm{TiO}_{2}$ can also be calculated from Figure 3. Neat $\mathrm{TiO}_{2}$ particles are stable throughout the test, while not for the modified $\mathrm{TiO}_{2}$. Therefore, the grafting level is $47.0 \%(100 \%-53.0 \%=47 \%)$, which is higher than the literature reports.

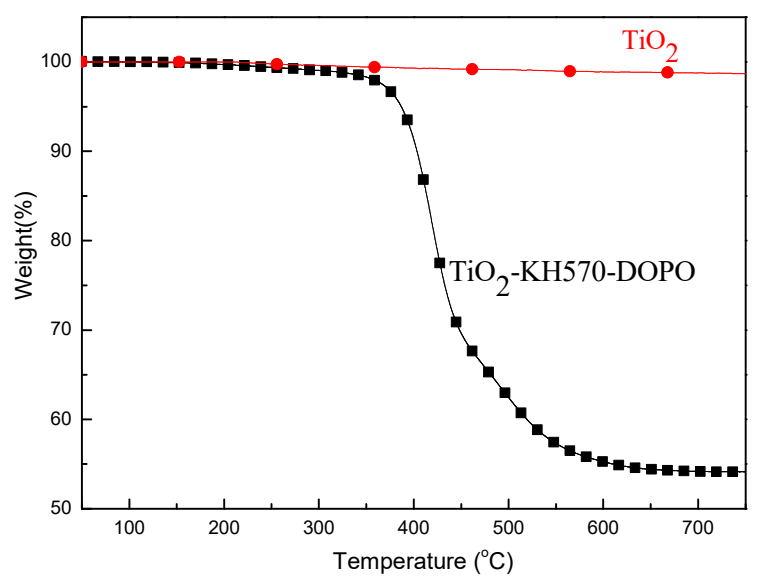

Figure 3. Thermogravimetric analysis (TGA) curves of $\mathrm{TiO}_{2}$ and $\mathrm{TiO}_{2}-\mathrm{KH} 570-\mathrm{DOPO}$ under air atmosphere. 


\subsubsection{Surface Morphology}

The TEM images of $\mathrm{TiO}_{2}$ and $\mathrm{TiO}_{2}-\mathrm{KH} 570-\mathrm{DOPO}$ are shown in Figure 4. As shown in Figure $4 \mathrm{a} 1, \mathrm{a} 2$, neat $\mathrm{TiO}_{2}$ particles tend to form self-aggregations because of the abundant hydroxy groups on the surface. After the introduction of KH570-DOPO (Figure $4 \mathrm{~b} 1, \mathrm{~b} 2$ ), this problem is greatly restricted. As a result, smaller aggregations can be observed. Overall, it can be concluded that $\mathrm{TiO}_{2}-\mathrm{KH} 570-\mathrm{DOPO}$ has been successfully prepared based on the results from FTIR, TGA and TEM.

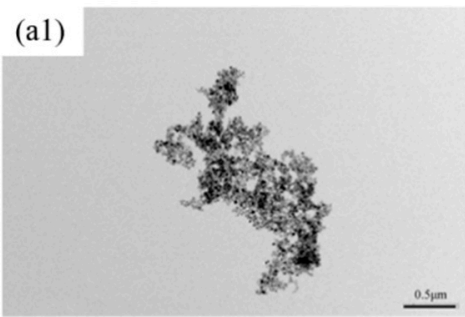

(b1)

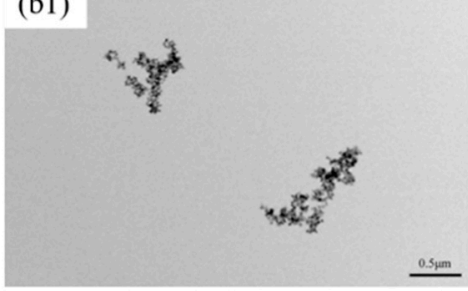

(a2)

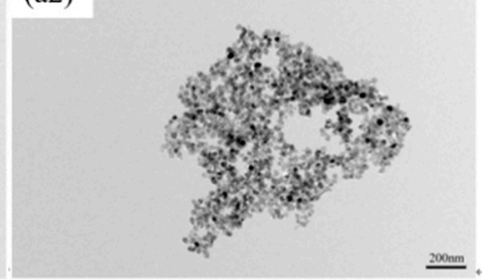

(b2)

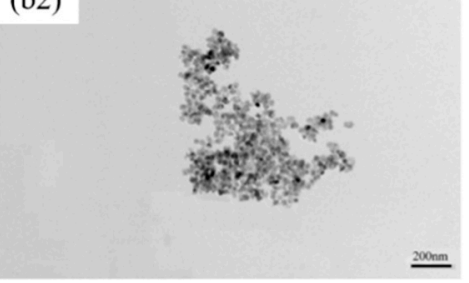

Figure 4. Transmission electron microscopy (TEM) image of (a1,a2) $\mathrm{TiO}_{2}$ and (b1,b2) $\mathrm{TiO}_{2}-\mathrm{KH} 570-\mathrm{DOPO}$.

\subsection{Characterization of FPUF}

\subsubsection{Flame Retardancy}

Microscale combustion calorimetry (MCC) is performed in order to investigate the combustion behavior of FPUF blends. The heat release rate (HRR), the temperature at which the peak heat release rate (pHRR) occurs (TP), as well as the total heat released (THR), can be obtained from this test. The HRR curves of the FPUF materials are shown in Figure 5, and other results are summarized in Table 1.

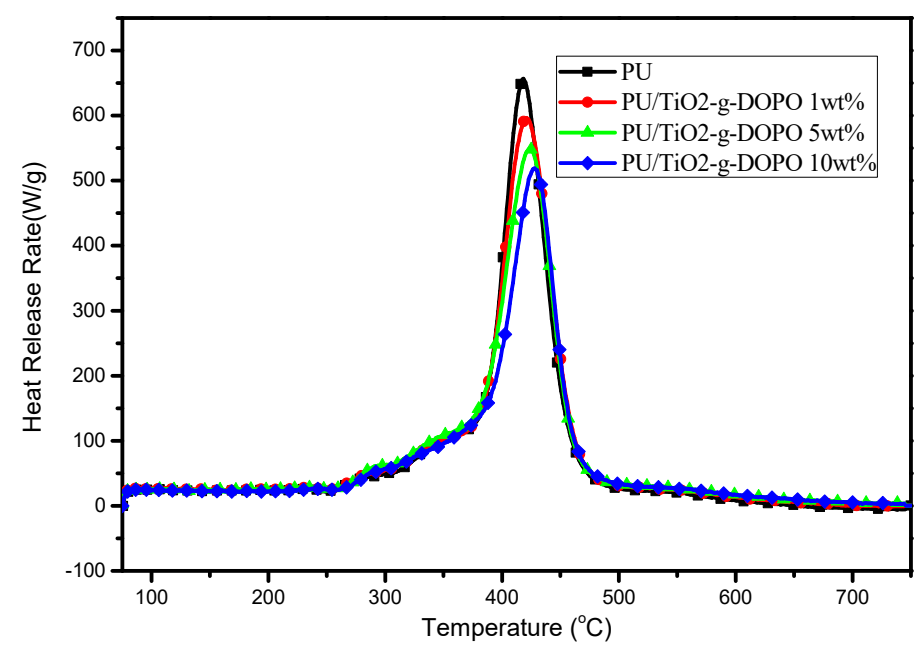

Figure 5. Heat release rate (HRR) curves of neat flexible polyurethane foam (FPUF) and flame retardant FPUF blends. 
Table 1. The key data obtain from microscale combustion calorimetry (MCC) tests for neat flexible polyurethane foam (FPUF) and flame retardant FPUF blends.

\begin{tabular}{cccc}
\hline Samples & pHRR/(W/g) & THR/(kJ/g) & $\mathbf{T}_{\mathbf{P}} /{ }^{\circ} \mathbf{C}$ \\
\hline S0 & 657.0 & 28.9 & 418.4 \\
S1 & $596.5(\downarrow 9.3 \%)$ & $28.5(\downarrow 1.4 \%)$ & $421.1(+2.7)$ \\
S5 & $549.7(\downarrow 16.3 \%)$ & $27.7(\downarrow 4.2 \%)$ & $423.9(+5.5)$ \\
S10 & $519.2(\downarrow 21.0 \%)$ & $26.8(\downarrow 7.3 \%)$ & $427.8(+9.4)$ \\
\hline
\end{tabular}

It can be seen from Figure 5 and Table 1 that the pHRR and THR values of flame retardant FPUF blends are gradually decreased with the increasing loading of $\mathrm{TiO}_{2}-\mathrm{KH} 570-\mathrm{DOPO}$, and both two parameters reach their maximum values ( $512.9 \mathrm{~W} / \mathrm{g}$ for $\mathrm{pHRR}$ and $26.8 \mathrm{~kJ} / \mathrm{g}$ for THR) at $10 \%$ incorporation of the nanoparticles. The $T_{P}$ values of the blends exhibits a similar tendency. A $9.4{ }^{\circ} \mathrm{C}$ delay can be found for the $\mathrm{S} 10$ sample. It has been reported that $\mathrm{TiO}_{2}$ takes effect in condensed phase by constructing dense and continuous char residues [13], while DOPO reacts in the gas phase as the radical scavenger [18]. As a result, the fire resistance of FPUR blends can be significantly enhanced.

\subsubsection{Thermal Stability}

The TGA curves of FPUF and FPUF blends under air atmosphere are shown in Figure 6 and the key data collected from TGA curves are given in Table 2. It is suggested that neat FPUF sample exhibits a two-step degradation pathway with $\mathrm{T}_{-5 \%}$ and $\mathrm{T}_{-50 \%}$ values of 278 and $374{ }^{\circ} \mathrm{C}$. The first step corresponds to the decomposition of the polymer main chain; the second step stands for the pyrosis of transient char. By the incorporation of nanoparticles, the FPUF blends also show a two-step degradation routine. However, the $\mathrm{T}_{-5} \%$ and $\mathrm{T}_{-50} \%$ values of FPUF blends are slightly increased compared with those of neat FPUF sample. The char residues of FPUF and FPUF blends after the tests are also given in Table 2. Neat FPUF sample exhibits $0.4 \%$ char residue, while the flame retardant FPUF samples show the much higher char residues. With the presence of $10 \% \mathrm{TiO}_{2}-\mathrm{KH} 570-\mathrm{DOPO}$, a maximum of $9.0 \%$ residues can be observed. The more the char has formed, the better is the flame retardancy. These physical barriers effectively separate the heat and oxygen from the matrix, resulting in improvement of both the fire resistance and thermal stability of FPUF blends [29].

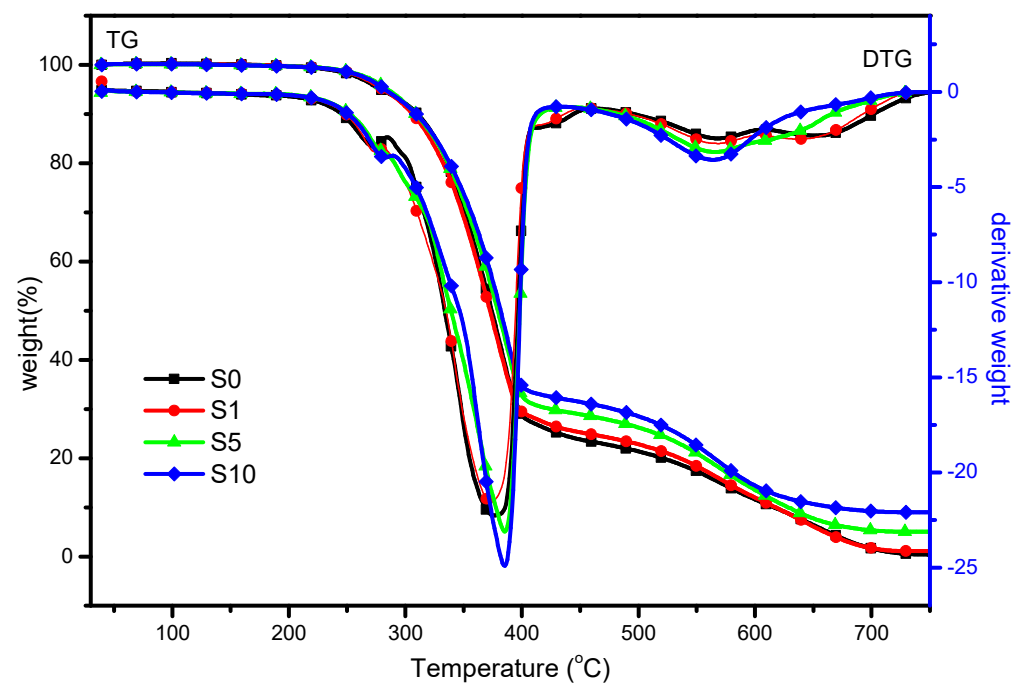

Figure 6. Thermogravimetric analysis (TGA) curves of neat flexible polyurethane foam (FPUF) and flame retardant FPUF blends under an air atmosphere. 
Table 2. The key data obtained from thermogravimetric analysis (TGA) tests for neat flexible polyurethane foam (FPUF) and flame retardant FPUF blends.

\begin{tabular}{|c|c|c|c|c|c|}
\hline \multirow{2}{*}{ Samples } & \multirow{2}{*}{$\begin{array}{c}T_{-5 \%}{ }^{a} \\
\left({ }^{\circ} \mathrm{C}\right)\end{array}$} & \multirow{2}{*}{$\begin{array}{c}T_{-50 \%}{ }^{b} \\
\left({ }^{\circ} \mathrm{C}\right)\end{array}$} & \multicolumn{2}{|c|}{ Weight Loss (wt \%) } & \multirow{2}{*}{ Residue(wt \%) } \\
\hline & & & Step 2 & Step 3 & \\
\hline So & 278 & 374 & 73.9 & 25.7 & 0.4 \\
\hline S1 & 284 & 380 & 72.8 & 26.1 & 2.6 \\
\hline S5 & 285 & 379 & 69.8 & 25.2 & 5.0 \\
\hline S10 & 282 & 381 & 67.3 & 23.7 & 9.0 \\
\hline
\end{tabular}

MCC and TGA results have indicated that $\mathrm{TiO}_{2}-\mathrm{KH} 570-\mathrm{DOPO}$ nanoparticles can improve the flame retardancy and thermal stability of FPUF. The kinetic analysis can provide additional information to the thermal oxidative degradation of the blends. In this study, the multiple heating rate kinetics method is used to estimate the apparent activation energy by applying the Flynn-Wall-Ozawa method [30-32] specifically derived for heterogeneous chemical reactions under linear heating rates $\left(2.5,5,7.5\right.$, and $\left.10^{\circ} \mathrm{C} / \mathrm{min}\right)$. The derivation of the Flynn-Wall-Ozawa method from the first principle was presented in 1965 [30]. As shown in Figure 7, the apparent activation energies are plotted as a function of $\alpha$.

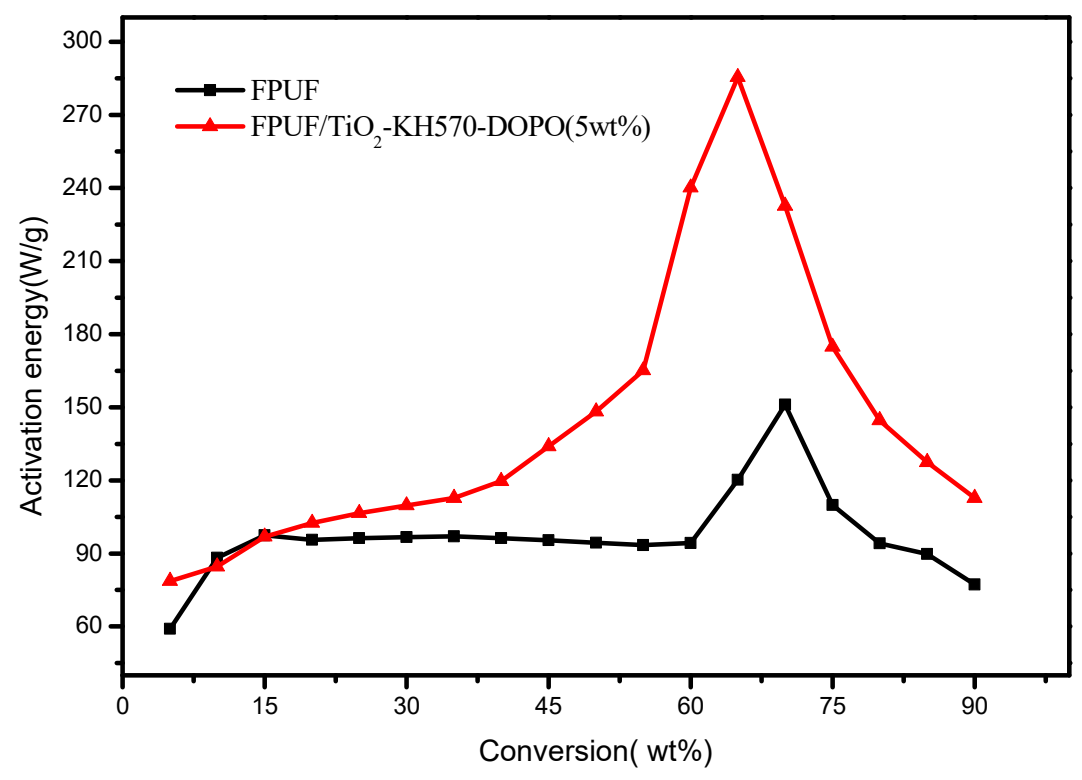

Figure 7. Activation energy of neat flexible polyurethane foam (FPUF) and flame retardant FPUF blends.

There is a small difference in the initial activation energies (when $\alpha$ is below 15\%) for the two samples. At low temperature, FPUF undergoes the radical peroxidation chain and the addition of $\mathrm{TiO}_{2}-\mathrm{KH} 570-\mathrm{DOPO}$ nanoparticles cannot influence the process. Moreover, activation energy of FPUF $/ \mathrm{TiO}_{2}-\mathrm{KH} 570-\mathrm{DOPO}$ increases rapidly as the degradation proceeds (when $\alpha$ is below $70 \%$ ), which is very different from that of FPUF. The high activation energies of $\mathrm{FPUF} / \mathrm{TiO}_{2}-\mathrm{KH} 570-\mathrm{DOPO}$ blend might be due to the effect of $\mathrm{TiO}_{2}$ and phosphorus on catalyzing the formation of carbonaceous char. Thus, the releasing rate of degradation volatiles is significantly reduced. The thermal stability and flame retardancy are thereby improved. The above results indicate that $\mathrm{TiO}_{2}-\mathrm{KH} 570-\mathrm{DOPO}$ might react in the gas phase as the radical scavenger. Details of the mechanism should be elicited in future work. 


\subsubsection{Condensed Phase Analysis}

The digital photographs of FPUF and flame retardant FPUF blends under different temperatures are shown in Figures 8 and 9. The corresponding area shrinkage is given in Figure 10. It is suggested that FPUF blends exhibit a much lower area decrease compared with those of neat FPUF samples, especially after $250{ }^{\circ} \mathrm{C}$. The incorporation of $\mathrm{TiO}_{2}-\mathrm{KH} 570$-DOPO takes effect in both the gas and condensed phase, resulting in better stability of the S5 sample.
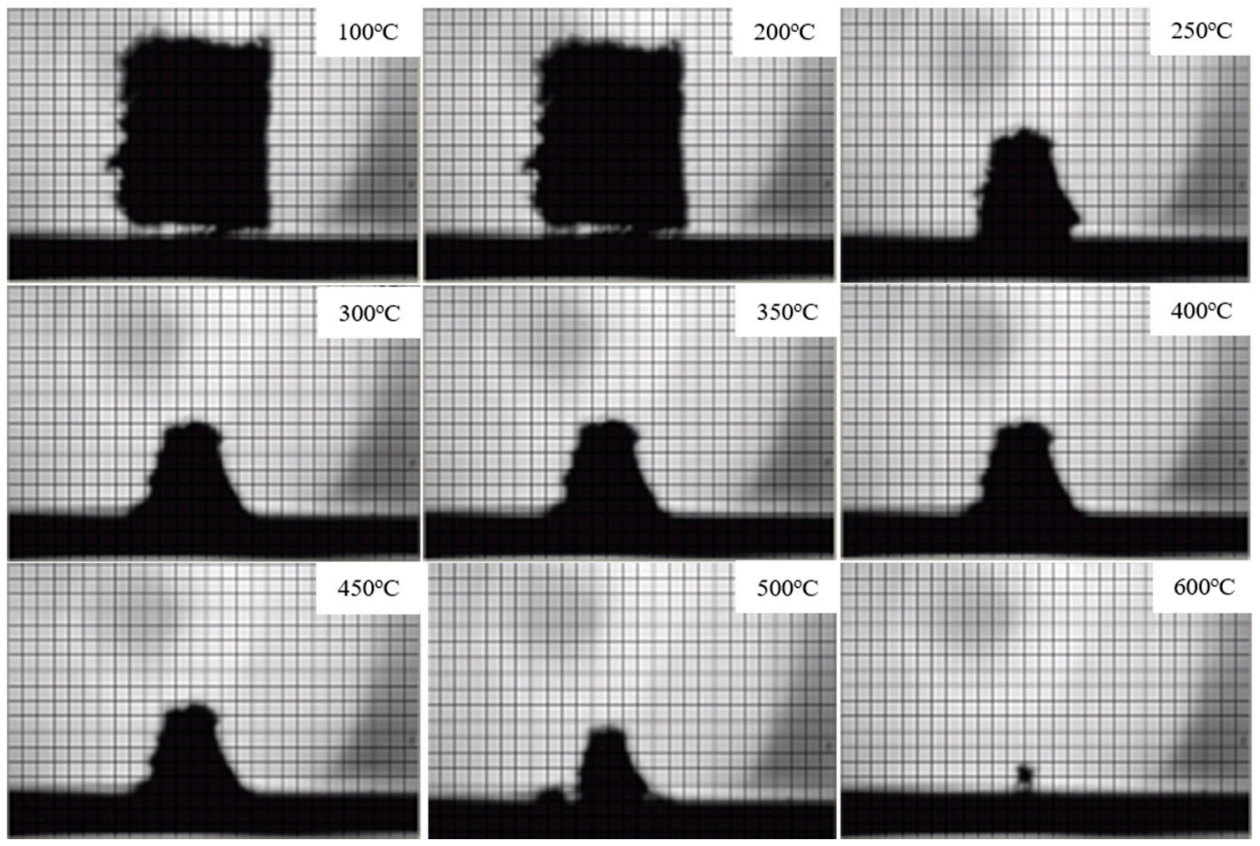

Figure 8. Digital photographs of neat flexible polyurethane foam (FPUF) samples at different temperatures.
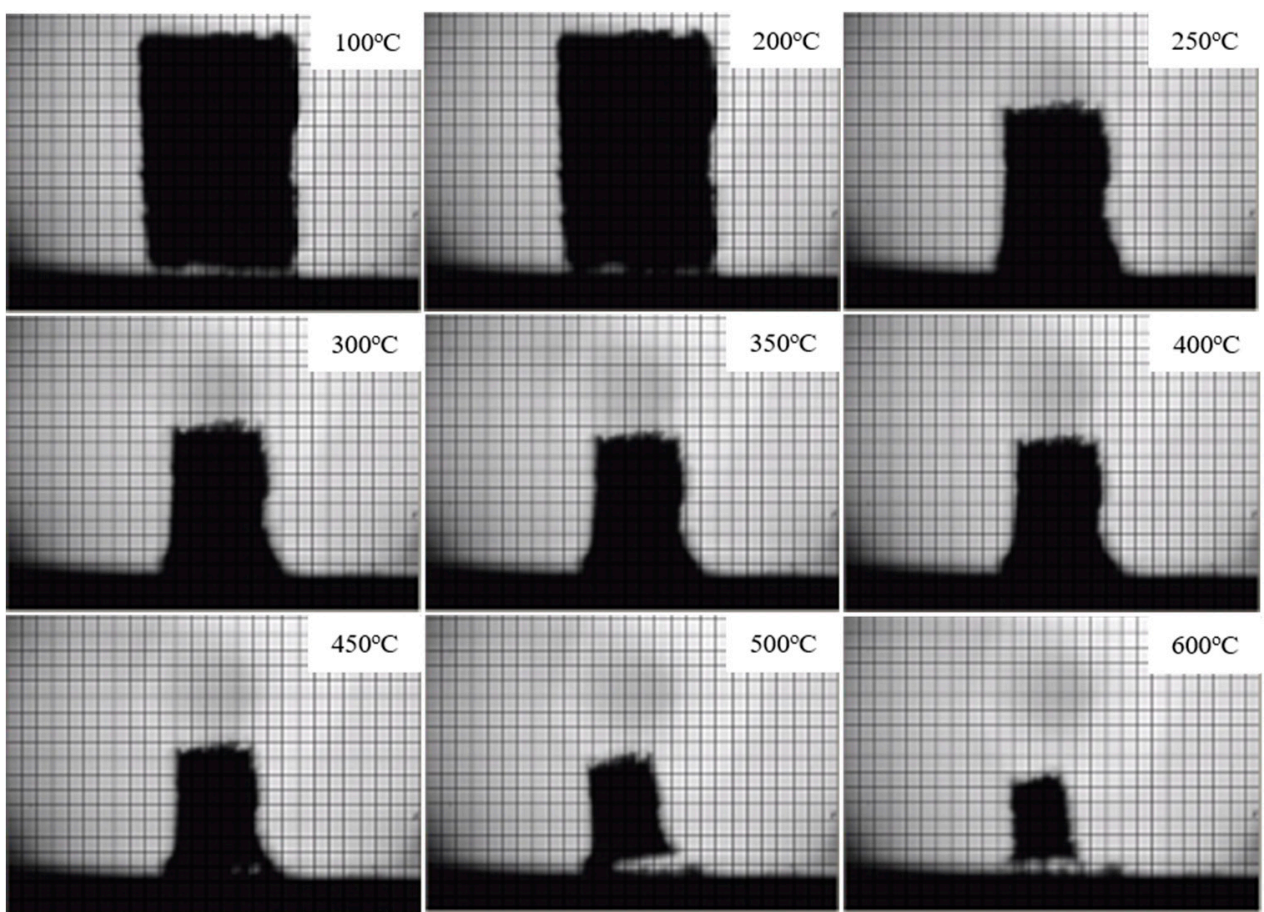

Figure 9. Digital photographs of flame retardant flexible polyurethane foam (FPUF) blends (S5) at different temperatures. 


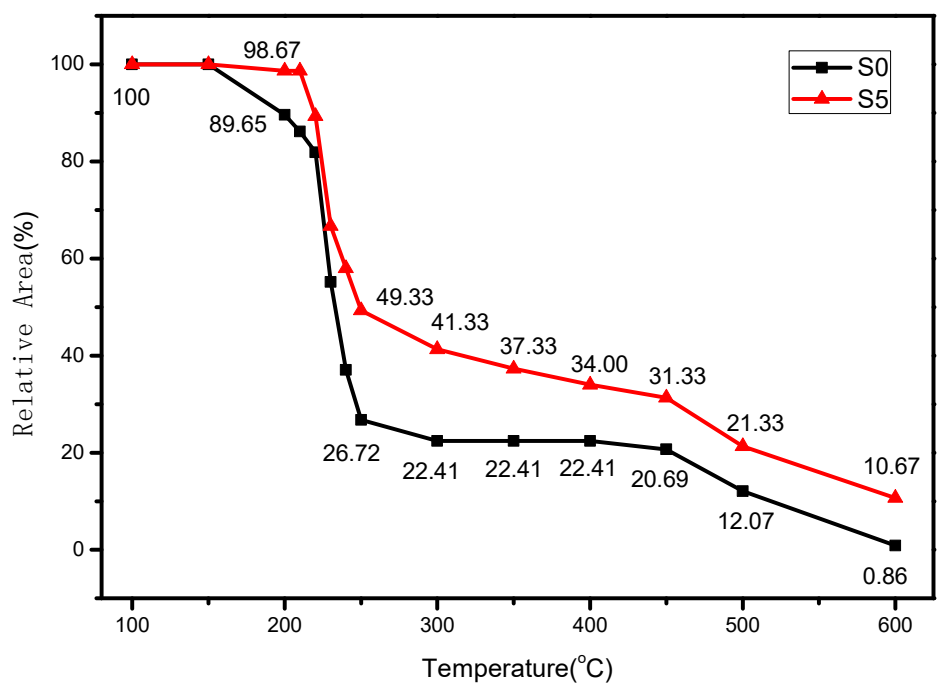

Figure 10. Corresponding area shrinkage for flexible polyurethane foam (FPUF) and FPUF blends.

The SEM images of char residues of FPUF and FPUF blends after MCC tests are shown in Figure 11. The morphology of neat FPUF sample exhibits discontinuous residual chars with lots of cracks and cavities. Heat and volatiles can easily penetrate these char layers, leading to poor fire resistance. For flame retardant FPUF blends, the construction of char layers has been significantly improved, especially for the S10 sample. It is reported that the combination of silicane and $\mathrm{TiO}_{2}$ is beneficial for producing physical barriers. The formation of compact and continuous char can prevent heat transfer and protect the underlying polymeric substrate, leading to the enhancement of flame retardancy [33].
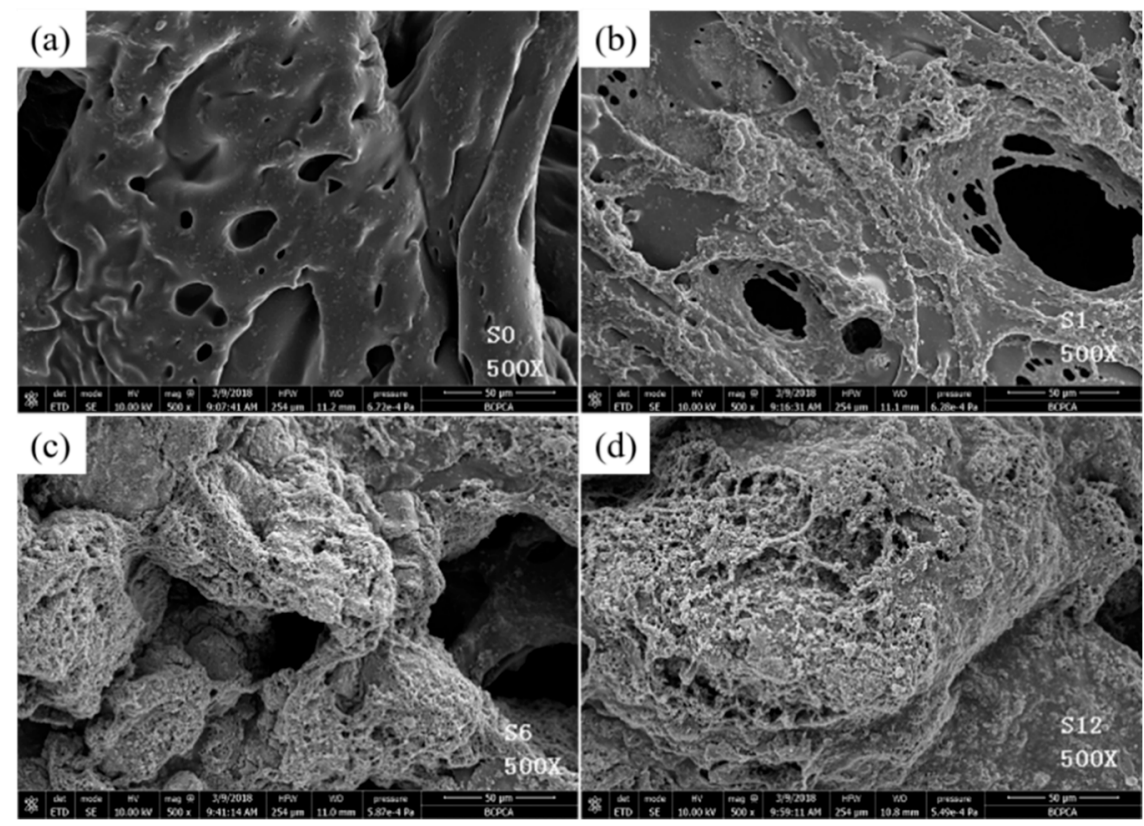

Figure 11. Scanning electron microscopy (SEM) images of char residues of (a) neat flexible polyurethane foam (FPUF), (b) S1, (c) S5 and (d) S10 blends after microscale combustion calorimetry (MCC) tests.

\section{Conclusions}

Multi-functional nanoparticles, $\mathrm{TiO}_{2}-\mathrm{KH} 570-\mathrm{DOPO}$, have been successfully prepared. The grafting level (47\%) of KH570-DOPO has been significantly improved by the existence of supercritical carbon dioxide. The introduction of $\mathrm{TiO}_{2}-\mathrm{KH} 570-\mathrm{DOPO}$ enhances the flame retardancy of FPUF. For 
the FPUF blend sample containing $10 \% \mathrm{TiO}_{2}-\mathrm{KH} 570-\mathrm{DOPO}$, the peak heat release rate was reduced from 657.0 to $519.2 \mathrm{~W} / \mathrm{g}$ ( $21 \%$ decrease), total heat release value also decreased from 28.9 to $26.8 \mathrm{~kJ} / \mathrm{g}$. Thermal analysis results suggested that $\mathrm{TiO}_{2}-\mathrm{KH} 570-\mathrm{DOPO}$ can affect the char forming process, leading to the formation of condensed residues.

Author Contributions: Conceptualization, Q.D.; Data curation, K.C.; Formal analysis, P.L.; Investigation, X.J.; Methodology, Y.T.; Supervision, S.S., F.W. and M.Y.

Funding: This research was funded by National Natural Science Foundation of China (Grant No. 21500403) and the Youth Innovation Promotion Association of CAS (Grant No. 2017041).

Acknowledgments: This work was financially supported by National Natural Science Foundation of China (Grant No. 21500403) and the Youth Innovation Promotion Association of CAS (Grant No. 2017041).

Conflicts of Interest: The authors declare no conflicts of interest.

\section{References}

1. Cho, J.H.; Vasagar, V.; Shanmuganathan, K.; Jones, A.R.; Nazarenko, S.; Ellison, C.J. Bioinspired catecholic flame retardant nanocoating for flexible polyurethane foams. Chem. Mater. 2015, 27, 6784-6790. [CrossRef]

2. Allan, D.; Daly, J.; Liggat, J.J. Thermal volatilisation analysis of TDI-based flexible polyurethane foam. Polym. Degrad. Stab. 2013, 98, 535-541. [CrossRef]

3. Chattopadhyay, D.K.; Webster, D.C. Thermal stability and flame retardancy of polyurethanes. Prog. Polym. Sci. 2009, 34, 1068-1133. [CrossRef]

4. Laufer, G.; Kirkland, C.; Morgan, A.B.; Grunlan, J.C. Exceptionally flame retardant sulfur-based multilayer nanocoating for polyurethane prepared from aqueous polyelectrolyte solutions. ACS Macro Lett. 2013, 2, 361-365. [CrossRef]

5. Troitzsch, J. Plastics Flammability Handbook; Hanser Publications: Munich, Germany, 2004

6. Dounis, D.V.; Wilkes, G.L. Structure-property relationships of flexible polyurethane foams. Polymer 1997, 38, 2819-2828. [CrossRef]

7. Jiao, C.; Wang, H.; Zhang, Z.; Chen, X. Preparation and properties of an efficient smoke suppressant and flame-retardant agent for thermoplastic polyurethane. Polym. Adv. Technol. 2017, 28, 1690-1698. [CrossRef]

8. Savas, L.A.; Deniz, T.K.; Tayfun, U.; Dogan, M. Effect of microcapsulated red phosphorus on flame retardant, thermal and mechanical properties of thermoplastic polyurethane composites filled with huntite \& hydromagnesite mineral. Polym. Degrad. Stab. 2017, 135, 121-129.

9. Chen, X.; Wang, W.; Jiao, C.A. Recycled environmental friendly flame retardant by modifying para-aramid fiber with phosphorus acid for thermoplastic polyurethane elastomer. J. Hazard. Mater. 2017, 331, 257-264. [CrossRef]

10. Kim, Y.S.; Davis, R.; Cain, A.A.; Grunlan, J.C. Development of layer-by-layer assembled carbon nanofiber-filled coatings to reduce polyurethane foam flammability. Polymer 2011, 52, 2847-2855. [CrossRef]

11. Smith, R.J.; Holder, K.M.; Ruiz, S.; Hahn, W.; Song, Y.X.; Lvov, Y.M.; Grunlan, J.C. Environmentally Benign Halloysite Nanotube Multilayer Assembly Significantly Reduces Polyurethane Flammability. Adv. Funct. Mater. 2017, 28, 1703289-1703297. [CrossRef]

12. Richardson, J.J.; Bjornmalm, M.; Caruso, F. Multilayer assembly Technology-driven layer-by-layer assembly of nanofilms. Science 2015, 348, aaa2491. [CrossRef] [PubMed]

13. Jin, X.D.; Sun, J.; Zhang, J.S.; Gu, X.Y.; Bourbigot, S.; Li, H.F.; Tang, W.F.; Zhang, S. Preparation of a Novel Intumescent Flame Retardant Based on Supramolecular Interactions and Its Application in Polyamide 11. ACS Appl. Mater. Interface 2017, 9, 24964-24975. [CrossRef] [PubMed]

14. Li, H.F.; Hu, Z.W.; Zhang, S.; Gu, X.Y.; Wang, H.J.; Jiang, P.; Zhao, Q. Effects of titanium dioxide on the flammability and char formation of water-based coatings containing intumescent flame retardants. Prog. Org. Coat. 2015, 78, 318-324. [CrossRef]

15. Apaydin, K.; Laachachi, A.; Ball, V.; Jimenez, M.; Bourbigot, S.; Ruch, D. Layer-by-layer deposition of a $\mathrm{TiO}_{2}$-filled intumescent coating and its effect on the flame retardancy of polyamide and polyester fabrics. Colloids Surf. A Physicochem. Eng. Asp. 2015, 469, 1-10. [CrossRef] 
16. Jiang, P.; Gu, X.Y.; Zhang, S.; Sun, J.; Xu, R.W.; Bourbigot, S.; Duquesne, S.; Casetta, M. Flammability and thermal degradation of poly (lactic acid)/polycarbonate alloys containing a phosphazene derivative and trisilanollsobutyl POSS. Polymer 2015, 79, 221-231. [CrossRef]

17. Zhang, Y.; Yu, B.; Wang, B.B.; Liew, K.M.; Song, L.; Wang, C.M.; Hu, Y. Highly Effective P-P synergy of a Novel DOPO-based Flame Retardant for Epoxy Resin. Ind. Eng. Chem. Res. 2017, 56, 1245-1255. [CrossRef]

18. Fang, Y.Y.; Qian, L.J.; Huang, Z.G.; Tang, S.; Qiu, Y. Synergistic charring effect of triazinetrione-alkyl-phosphinate and phosphaphenanthrene derivatives in epoxy thermosets. RSC Adv. 2017, 7, 46505-46513. [CrossRef]

19. Lin, H.J.; Yan, H.; Liu, B.; Wei, L.Q.; Xu, B.S. The influence of KH-550 on properties of ammonium polyphosphate and polypropylene flame retardant composites. Polym. Degrad. Stab. 2011, 96, 1382-1388. [CrossRef]

20. Ren, Y.; Yuan, D.D.; Li, W.M.; Cai, X.F. Flame retardant efficiency of KH-550 modified urea-formaldehyde resin cooperating with ammonium polyphosphate on polypropylene. Polym. Degrad. Stab. 2018, 151, 160-171. [CrossRef]

21. Dong, Q.X.; Ding, Y.F.; Wen, B.; Wang, F.; Dong, H.C.; Zhang, S.M.; Wang, T.X.; Yang, M.S. Improvement of thermal stability of polypropylene using DOPO-immobilized silica nanoparticles. Colloids Polym. Sci. 2012, 290, 1371-1380. [CrossRef]

22. Dong, Q.X.; Liu, M.M.; Ding, Y.F.; Wang, F.; Gao, C.; Liu, P.; Wen, B.; Zhang, S.M.; Yang, M.S. Synergistic effect of DOPO immobilized silica nanoparticles in the intumescent flame retarded polypropylene composites. Polym. Adv. Technol. 2013, 24, 732-739. [CrossRef]

23. Stojanović, D.B.; Brajović, L.; Orlović, A.; Dramlić, D.; Radmilović, V.; Uskoković, P.S.; Aleksića, R. Transparent PMMA/silica nanocomposites containing silica nanoparticles coating under supercritical conditions. Prog. Org. Coat. 2013, 76, 626-631. [CrossRef]

24. Zhao, J.; Zhang, L.Q.; Chen, T.; Hu, H.; Zhang, L.; Xue, H.; Hu, H.Q. Supercritical Carbon-Dioxide-Assisted Deposition of Pt Nanoparticles on Graphene Sheets and Their Application as an Electrocatalyst for Direct Methanol Fuel Cells. J. Phys. Chem. C 2012, 116, 21374-21381. [CrossRef]

25. Kuang, T.R.; Chen, F.; Chang, L.Q.; Zhao, Y.N.; Fu, D.J.; Gong, X.; Peng, X.F. Facile Preparation of Open-cellular Porous Poly (L-lactic acid) Scaffold by Supercritical Carbon Dioxide Foaming for Potential Tissue Engineering Applications. Chem. Eng. J. 2017, 307, 1017-1025. [CrossRef]

26. Chen, S.H.; Wang, X.D.; Ma, X.Q.; Wang, K.S. Morphology and properties of polypropylene $/$ nano-CaCO 3 , composites prepared by supercritical carbon dioxide-assisted extrusion. J. Mater. Sci. 2016, 51, 708-718. [CrossRef]

27. Zhou, Y.S.; Yu, J.R.; Wang, X.X.; Wang, Y.; Zhu, J.; Hu, Z.M. Preparation of $\mathrm{KH}^{2}$ 70-SiO 2 and their modification on the MF/PVA composite membrane. Fibers Polym. 2015, 16, 1772-1780. [CrossRef]

28. Wang, X.; Hu, Y.; Song, L.; Yang, H.Y.; Xing, W.Y.; Lu, H.D. Synthesis and characterization of a DOPO-substituted organophosphorus oligomer and its application in flame retardant epoxy resins. Prog. Org. Coat. 2011, 71, 72-82. [CrossRef]

29. Jin, X.D.; Chen, C.; Sun, J.; Zhang, X.; Gu, X.Y.; Zhang, S. The synergism between melamine and expandable graphite on improving the flame retardancy of polyamide 11. High Perform. Polym. 2017, 29, 77-86. [CrossRef]

30. Ozawa, T. A new method of analyzing thermogravimetric data. Bull. Chem. Soc. Jpn. 1965, 38, 1881-1886. [CrossRef]

31. Flynn, J.H.; Wall, L.A. A quick direct method for determination of activation energy from thermogravimetric data. J. Polym. Sci. B Polym. Lett. 1966, 4, 323-328. [CrossRef]

32. Flynn, J.H. The isoconversional method for determination of energy of activation at constant heating rates-Corrections for the Doyle approximation. J. Therm. Anal. 1983, 27, 95-102. [CrossRef]

33. Jin, X.D.; Gu, X.Y.; Chen, C.; Tang, W.F.; Li, H.F.; Liu, X.D.; Bourbigot, S.; Zhang, Z.W.; Sun, J.; Zhang, S. The fire performance of polylactic acid containing a novel intumescent flame retardant and intercalated layered double hydroxides. J. Mater. Sci. 2017, 52, 12235-12250. [CrossRef]

(C) 2019 by the authors. Licensee MDPI, Basel, Switzerland. This article is an open access article distributed under the terms and conditions of the Creative Commons Attribution (CC BY) license (http:/ / creativecommons.org/licenses/by/4.0/). 